\title{
Microbial degradation of isosaccharinic acid under conditions representative for the far field of radioactive waste disposal
} facilities

\author{
Gina Kuippers $^{1, *}$, Najt Milad Bassil ${ }^{1}$, Christopher Boothman ${ }^{1}$, Nicholas Bryan ${ }^{2}$ and Jonathan R. Lloyd ${ }^{1}$
}

1 Research Centre for Radwaste and Decommissioning \& Williamson Research Centre for Molecular Environmental Science, School of Earth, Atmospheric and Environmental Sciences, The University of Manchester, Oxford Road, Manchester M13 9PL, UK

2 National Nuclear Laboratory, Chadwick House, Birchwood, Warrington WA3 6AE, UK

[Received 24 February 2015; Accepted 10 June 2015; Associate Editor: Nicholas Evans]

\section{ABSTRACT}

It is UK Government policy to dispose of higher activity radioactive waste through geological disposal into an engineered deep underground geological disposal facility (GDF; DECC, 2014). Those wastes include low-level (LLW) and intermediate-level (ILW) radioactive wastes that are very heterogeneous, containing a range of inorganic and organic materials, the latter including cellulosic items. After closure of the GDF, eventual resaturation with groundwater is expected, resulting in the development of a hyperalkaline environment due to the proposed use of a cementitious backfill. Under these high-pH conditions, cellulose is unstable and will be degraded chemically, forming a range of water-soluble, low molecular weight compounds, of which the most abundant is isosaccharinic acid (ISA). As ISA is known to form stable soluble complexes with a range of radionuclides, thereby increasing the chance of radionuclide transport, the impact of microbial metabolism on this organic substrate was investigated to help determine the role of microorganisms in moderating the transport of radionuclides from a cementitious GDF. Anaerobic biodegradation of ISA has been studied recently in high-pH cementitious ILW systems, but less work has been done under anaerobic conditions at circumneutral conditions, more representative of the geosphere surrounding a GDF. Here we report the fate of ISA in circumneutral microcosms poised under aerobic and anaerobic conditions; the latter with nitrate, Fe(III) or sulfate added as electron acceptors. Data are presented confirming the metabolism of ISA under these conditions, including the direct oxidation of ISA under aerobic and nitrate-reducing conditions and the fermentation of ISA to acetate, propionate and butyrate prior to utilization of these acids during Fe(III) and sulfate reduction. The microbial communities associated with these processes were characterized using 16S rRNA gene pyrosequencing. Methane production was also quantified in these experiments, and the added electron acceptors were shown to play a significant role in minimizing methanogenesis from ISA and its breakdown products.

Keywords: isosaccharinic acid, complex, radionuclide mobility, biodegradation, nuclear waste, geological disposal.

* E-mail: gina.kuippers@manchester.ac.uk

DOI: $10.1180 /$ minmag.2015.079.6.19

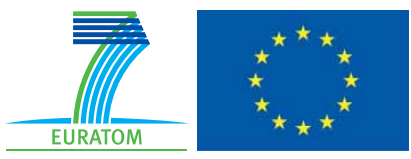

The publication of this research has been funded by the European Union's European Atomic Energy Community's (Euratom) Seventh Framework programme FP7 (2007-2013) under grant agreements $n^{\circ} 249396$, SecIGD, and $n^{\circ} 323260$, SeclGD2. 


\section{G. KUIPPERS ETAL.}

\section{Introduction}

IT is UK Government policy to dispose of LLW and ILW radioactive waste, comprising the largest volume of radioactive waste of the national inventory, into an engineered deep underground geological disposal facility (GDF). The majority of the ILW and a small portion of the LLW containing long-lived radionuclides (DECC, 2014), will be encapsulated in grout within steel drums, and then encased in concrete in vaults excavated into a suitable geological formation. The LLW and ILW vaults will become reducing after closure of the GDF, and a hyperalkaline environment will be created when groundwater penetrates the engineered barrier system of a cement-dominated GDF.

ILW and LLW wastes are very heterogeneous, and contain substantial amounts of cellulosic material, including paper, filters and cotton. These cellulosic compounds are known to be degraded under the anoxic hyperalkaline repository conditions that are expected in situ, leading to the production of a range of soluble organic compounds (Glaus et al., 1999). During this alkaline hydrolysis, glucose units are eliminated from the cellulose chain in a stepwise process, known as a 'peeling-reaction' (e.g. Van Loon et al., 1999; Pavasars et al., 2003), which is initiated at the reducing end group (a reactive aldehyde carbonyl). In contrast, the $\beta-1,4$ glycosidic linkages are alkalistable and cannot be reduced (Askarieh et al., 2000). The peeling reaction competes with another abiotic reaction, the so-called 'stopping-reaction', which is either a chemical transformation taking place at the end of the cellulose molecule or a physical termination which takes place in highly crystalline regions (e.g. Van Loon et al., 1999; Vercammen et al., 1999; Pavasars et al., 2003). Since the reaction can be reinitiated by the so-called 'midchain scission', which is a random cleavage of glycosidic bonds within the polysaccharide chain, all cellulose may be degraded over prolonged timescales (Glaus and van Loon, 2008).

In cementitious pore waters, as they are expected in a GDF, isosaccharinic acid (ISA, $\mathrm{C}_{6} \mathrm{H}_{12} \mathrm{O}_{6}$ ) has been identified as the main product of the alkaline degradation of cellulosic material (Whistler and BeMiller, 1958; van Loon and Glaus, 1998; Glaus et al., 1999; Knill and Kennedy, 2003), supported by further results from a long-term study by Pavasars et al. (2003) and also by Glaus and van Loon (2008). In the presence of divalent cations, such as $\mathrm{Ca}^{2+}$, common in the cementitious backfill of a GDF where calcium concentrations are expected to be high, ISA binds to calcium ions to form the divalent salt $\mathrm{Ca}(\mathrm{ISA})_{2}$ (Vercammen et al., 1999).

Various studies have shown that ISA can also form stable soluble complexes with metals and radionuclides, including those from the lanthanide and actinide series, particularly Am(III) (Tits et al., 2005), Eu(III) (Vercammen et al., 2001; Tits et al., 2005), Ni(II) (Warwick et al., 2003), Np(IV) (Rai et al., 2003; Gaona et al., 2008), Th(IV) (Vercammen et al., 2001; Tits et al., 2005), and U(IV) (Warwick et al., 2004). Since ISA forms such strong soluble complexes with radionuclides, there is concern that ISA may increase radionuclide migration when the groundwater resaturates the GDF, thereby increasing the likelihood of transport from the engineered barrier system and through the geosphere. Conservative assumptions in modelling estimate that considerable amounts of up to $0.1 \mathrm{M}$ ISA can be produced (Bradbury and Sarott, 1995), which are considered chemically stable under alkaline conditions (Bradbury and Sarott, 1995), and sorption on cement is minor (Bradbury and Sarott, 1995; Van Loon et al., 1997), increasing the interest in the potential biodegradation of ISA by subsurface microorganisms.

Recent studies have demonstrated that the geochemical conditions in a GDF may not be sufficiently harsh to prevent microbial metabolism, with a range of aerobic and anaerobic microorganisms surviving highly alkaline (up to $\mathrm{pH} 12$; Rizoulis et al., 2012; Williamson et al., 2013) and/or radioactive conditions (Booth, 1987; Brown et al., 2014). Therefore microbial metabolism may have the potential to control the mobility of priority radionuclides via a range of mechanisms (reviewed in Lloyd and Macaskie, 2000), moderating their transport after GDF closure. The utilization of ISA by aerobic organisms is well known (Strand et al., 1984; Bailey, 1986), but has not been reported widely under anaerobic conditions, although a recent study has demonstrated that ISA can serve as an electron donor for anaerobic metabolism (e.g. nitrate reduction) under alkaline conditions ( $\mathrm{pH} 10$; Bassil et al., 2014). However, if ISA degradation processes are incomplete and ISA should escape from the alkaline near-field of a cementitious GDF, there is little information on its fate in the largely anoxic circumneutral far-field geosphere, dominated in UK groundwaters by the potential electron acceptor sulfate (Bond and Tweed, 1995). It should be noted that at $\mathrm{pH} 10$ and above, sulfate reduction using a range of electron donors (Rizoulis et al., 2012), including ISA (Bassil et al., 2014) is 
minimal over the extended periods (several months) tested thus far.

In this study an enrichment-cultivation approach was applied to study the fate of ISA under such circumneutral conditions. Sediments from a lime workings site near Buxton (Rizoulis et al., 2012; Williamson et al., 2013) which has areas with elevated $\mathrm{pH}$ values and high-Ca concentrations were retrieved, consistent with those of an ILW radioactive waste disposal facility ( $\mathrm{pH} \sim 12.5, \mathrm{Ca}^{2+}$ $\sim 20 \mathrm{mM}$; NDA, 2010), and is known to contain microorganisms able to degrade ISA (Bassil et al., 2014). Microcosms ( $\mathrm{pH} \mathrm{7)}$ were inoculated with the lime workings site sediments, simulating conditions of the surrounding geosphere of a GDF under different possible redox conditions, using $\mathrm{NO}_{3}^{-}, \mathrm{Fe}(\mathrm{III}), \mathrm{SO}_{4}^{2-}$ or $\mathrm{CO}_{2}$ as electron acceptors. A multidisciplinary approach was adopted to elucidate the fate of ISA, including geochemical, microbiological and microscopy techniques.

\section{Material and methods}

\section{Sediment acquisition}

Surface sediment samples were collected from a depth of $\sim 20 \mathrm{~cm}$, at a site contaminated by legacy lime workings at Harpur Hill, Buxton in Derbyshire, UK. The study site showed a $\mathrm{pH}$ ranging from $c .6 .5$ to 11 with high calcium and silicate concentrations, and for this study samples were collected from a marginal area and a $\mathrm{pH}$ of 6.8. The samples were stored in the dark at $4^{\circ} \mathrm{C}$ until analysis.

\section{$\mathrm{Ca}(I S A)_{2}$ preparation}

$\mathrm{Ca}(\mathrm{ISA})_{2}$ was prepared from $\alpha$-lactose monohydrate and $\mathrm{Ca}(\mathrm{OH})_{2}$ following the protocol of Vercammen et al. (1999).

\section{Enrichment cultures}

Enrichment cultures were grown by incubating a sediment inoculum $(1 \% \mathrm{vol} / \mathrm{vol})$ in a minimal medium containing $30 \mathrm{mM} \mathrm{NaHCO} 3,4.7 \mathrm{mM}$ $\mathrm{NH}_{4} \mathrm{Cl}, \quad 4.4 \mathrm{mM} \quad \mathrm{NaH}_{2} \mathrm{PO}_{4} \cdot \mathrm{H}_{2} \mathrm{O}, 1.3 \mathrm{mM} \mathrm{KCl}$, and $0.3 \mathrm{ml}$ of mineral and vitamin stock solutions (Lovley et al., 1984). The $\mathrm{pH}$ of the medium was adjusted to 7 with $\mathrm{NaOH}$ then de-aerated with a $\mathrm{N}_{2} / \mathrm{CO}_{2}(80: 20)$ gas mixture for $30 \mathrm{~min}$. $\mathrm{Ca}(\mathrm{ISA})_{2}$ was added to a final concentration of $1.5 \mathrm{mM}$ as sole carbon source and electron donor. The medium was distributed over four different anaerobic experiments using the following terminal electron acceptors (TEAs) either $24 \mathrm{mM} \mathrm{NaNO}$, $\mathrm{Fe}$ (III) oxyhydroxide added as a slurry to a concentration of $20 \mathrm{mmol} \mathrm{l}^{-1}, 12 \mathrm{mM} \mathrm{Na} \mathrm{SO}_{4}$ or "no added electron acceptor' $\left(\mathrm{CO}_{2}\right.$ served as the sole electron acceptor in these experiments). For each TEA three different controls were prepared in triplicate, comprising (1) a test control containing ISA, the respective TEA and an active inoculum, (2) a control with no added electron donor (no ISA) and (3) an 'abiotic' sterile control that contained ISA and the appropriate TEA, but was autoclaved to kill any active microorganisms. All microcosms were prepared in serum bottles sealed with butyl stoppers that were flushed with an $\mathrm{N}_{2} / \mathrm{CO}_{2}(80: 20)$ gas mixture for $5 \mathrm{~min}$ prior to autoclaving and later inoculation and incubation in the dark at $20^{\circ} \mathrm{C}$. Aerobic experiments were also set up the same way, using the same medium (but lacking $30 \mathrm{mM}$ $\mathrm{NaHCO}_{3}$ ), but here the bottles were closed with a foam bung to facilitate oxygen transfer.

Samples were collected aseptically and frozen immediately at $-20^{\circ} \mathrm{C}$ until further analysis. After microbial activity had reached a steady state, monitored by turbidity and $\mathrm{pH}$, the cultures were re-subcultured into fresh medium, using a $1 \%(\mathrm{vol} / \mathrm{vol})$ inoculum, and incubated for another incubation period. Data presented were obtained from this subculture of the sediment incubation experiments.

\section{Analytical techniques}

The $\mathrm{pH}$ of samples from the microcosms was measured with a calibrated Denver Instrument digital meter ( $\mathrm{pH} \mathrm{4,7}$ and 12). Bacterial growth was monitored over the length of incubation by optical density (OD) measurements at $600 \mathrm{~nm}$ compared to a blank, containing only growth medium and $\mathrm{Ca}(\mathrm{ISA})_{2}$. The Ferrozine spectrophotometric assay was used to quantify Fe(II) and total $\mathrm{Fe}$ (after reaction with hydroxylamine) by comparison with known standards at a wavelength of $562 \mathrm{~nm}$ (Lovley and Phillips, 1987). In addition, light microscopy was performed on key samples to check for microbial growth under both transparent light and fluorescent light using a Zeiss Axioscope Microscope fitted with an 100x ACHROPLAN lens (No: 440081), the latter using Hoechst 33342 nucleic acid stain. 
GC-TCD

The gases oxygen and methane were analysed in the headspace of the sediment incubation experiments with an Agilent 7890A Gas Chromatograph, fitted with a 7697A headspace autosampler, connected to an Agilent 7890 Thermal Conductivity Detector (TCD). The chromatograph was equipped with a HP Molesieve column $(30 \mathrm{~m} \times 25 \mu \mathrm{m} \times 0.53 \mathrm{~mm})$. The TCD was heated to $180^{\circ} \mathrm{C}$ and the split/splitless inlet was heated to $250^{\circ} \mathrm{C}$ with a backpressure of $1.36 \mathrm{psi}$ and argon as carrier gas was used at a flow rate of $104 \mathrm{ml} \mathrm{min}^{-1}$. For analysis the autosampler was set to a constant injection of $1 \mathrm{ml}$ with pressure equilibration, and a split ratio of 1:100. After injection into a loop of $1 \mathrm{ml}$ volume, the sample was forwarded to the oven in an isothermal run at $50^{\circ} \mathrm{C}$ which took $12 \mathrm{~min}$. The column flow was of $6 \mathrm{ml} \mathrm{min}^{-1}$ together with a reference flow at $9 \mathrm{ml} \mathrm{min}^{-1}$.

\section{lon-exchange chromatography}

Sulfate, nitrate, nitrite, organic acids and ISA were analysed using ion exclusion high performance liquid chromatography (IE-HPLC), using a Dionex ICS5000 Dual Channel on Chromatograph, fitted with a Dionex AS-AP auto sampler, connected to a CD20 conductivity detector. The chromatograph was equipped with a Dionex Capillary $(50 \mathrm{~mm} \times$ $0.4 \mathrm{~mm}$ ) AG11-HC $4 \mu \mathrm{m}$ guard column and Dionex Capillary $(250 \mathrm{~mm} \times 0.4 \mathrm{~mm})$ AS11-HC $4 \mu \mathrm{m}$ analytical column. For background reduction a Dionex ACES300 Chemical Suppressor was used.

For analysis, frozen aliquots were thawed, vortexed, centrifuged and the supernatant transferred to microcentrifuge tubes at a 1:50 sample/ DIW ratio. The mobile phase (eluent) comprised a gradient of concentrated $\mathrm{KOH}$ which was mixed with high purity water at a flow rate of $0.015 \mathrm{ml} / \mathrm{min}$ and a backpressure of 3200 psi. $0.4 \mu \mathrm{l}$ was injected to a run that started at $1 \mathrm{mM} \mathrm{KOH}$ for $10 \mathrm{~min}$, increased then to $38 \mathrm{mM}$ up to minute 25 and then re-equilibrated to the initial value until $40 \mathrm{~min}$.

\section{DNA extraction and pyrosequencing}

Bacterial community structure was examined by extraction of DNA from $200 \mu$ of the sediment inoculum for the initial community and subcultured microcosms for the enrichment cultures using the MoBio PowerLyzer ${ }^{\mathrm{TM}}$ UltraClean Microbial DNA Isolation Kit (MoBio Laboratories, Inc., Carlsbad, CA, USA). PCR for amplicon pyrosequencing was performed using tagged fusion bacterial primers
27F (Lane, 1991) and 907R (Muyzer et al., 1995), targeting the V1-V5 hypervariable region of the bacterial 16S rRNA gene. Pyrosequencing PCR was performed using Roche's 'Fast Start High Fidelity PCR system' as described previously (Bassil et al., 2014, or Williamson et al., 2013). The pyrosequencing run was performed at the University of Manchester sequencing facility, using a Roche 454 Life Sciences GS Junior system. The 454 pyrosequencing reads were analysed using Qiime 1.8.0 release (Caporaso et al., 2010), and denoizing and chimera removal was performed in Qiime during OTU picking (at 97\% sequence similarity) with usearch (Edgar, 2010). Taxonomic classification of all reads was performed in Qiime, using the Ribosomal Database Project (RDP) at 90\% confidence threshold (Cole et al., 2009), while the closest GenBank match for the OTUs that contained the highest number of reads (the representative sequence for each OTU was used) was identified by Blastn nucleotide search. In addition, Qiime was used to prepare rarefaction curves for the samples.

\section{Results and discussion}

Microcosm experiments were conducted to determine the impact of a range of terminal electron accepting processes on the biodegradation of ISA at circumneutral $\mathrm{pH}$ as expected in the surrounding geosphere of a GDF. Results presented here focus on data collected from stable enrichment cultures that were prepared from the primary microcosms (i.e. the first subculture), with the exception of the headspace gas results that were obtained from the primary enrichment cultures. The analysis of these subcultured experiments was considered more robust, being separated from the geochemically more complex primary cultures by the biogeochemical selection pressures imposed by the highly selective media used, making the biogeochemical and microbiological data from these experiments easier to interpret. ISA degradation was recorded under all the conditions tested, ranging from the aerobic incubations (Fig. 1) to anaerobic incubations with either nitrate (Fig. 2a-c), Fe(III) (Fig. $2 d-f$ ) or sulfate (Fig. $3 a-c$ ) as electron acceptor or 'no added electron acceptor' (Fig. $3 d-$ e). In all cases, ISA was not degraded in the sterile controls, confirming a microbiological mechanism.

Biodegradation of ISA commenced immediately under aerobic and nitrate-reducing conditions, while there was a time lag of about seven days in the experiments under $\mathrm{Fe}(\mathrm{III})$-reducing and 


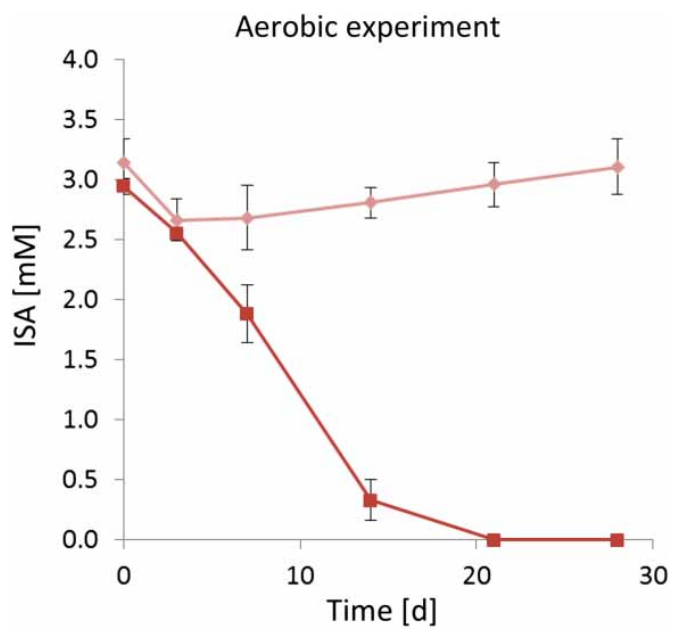

FIG. 1. Biodegradation of ISA by aerobic microbial cultures at a $\mathrm{pH}$ of 7. ISA concentration: ( $\square$ ) test condition with active microbial inoculum; $(\diamond)$ sterile control (autoclaved).

sulfate-reducing conditions. There was also pronounced ISA degradation, again after a lag period, in the 'no added electron acceptor' incubation, indicative of fermentation processes, in this case leading to the production of acetate, $n$-butyrate and minor levels of propionate and formate. After an initial lag phase ISA oxidation was complete within about 21 days under all conditions, apart from incubations with added $\mathrm{Fe}(\mathrm{III})$, where ISA was depleted after 28 days.

Under aerobic conditions, the rate of ISA degradation was consistent from the start of the incubation until almost complete depletion of all ISA in the test incubation by 14 days, while concentrations remained stable in the sterile control (Fig. 1). ISA degradation was accompanied by a drop in $\mathrm{pH}$ from 7 to 6 and a drop in turbidity from $\mathrm{OD}_{600 \mathrm{~nm}}=0.42$ to 0.13 (data not shown). The drop in $\mathrm{pH}$ is a result of equilibration with the atmosphere, which was possible since the aerobic microcosms were non-sealed. In the IC analysis no organic acids were detected, consistent with complete oxidation of ISA to $\mathrm{CO}_{2}$.

Under nitrate-reducing conditions, rapid ISA degradation was again noted until day 14 , and then slowed (Fig. 2a), accompanied by a decrease in the rate of nitrate reduction, which was converted to nitrite (Fig. 2b). During this time period, about 82\% of both the ISA and nitrate were removed, while only an additional $6 \%$ of these substrates were removed over the next 28 days. Incomplete ISA degradation indicated toxication due to elevated nitrite concentrations, which are considered to inhibit microbial metabolism (e.g. Shen et al., 2003). Only low amounts of the degradation product acetate were detected, along with very minor amounts of $n$-butyrate and propionate (Fig. 2c), indicating that ISA was degraded via denitrification to $\mathrm{CO}_{2}$ and another denitrification end-point, for example nitrogen. The $\mathrm{pH}$ in the denitrifying cultures remained stable, no methane was produced (Fig. 4) and, similar to the aerobic experiment, a drop in turbidity from 0.58 to 0.18 over 42 days of incubation was measured.

In the Fe(III)-reducing enrichment cultures, ISA degradation commenced after a lag phase of seven days and accelerated from day 14. Concomitantly with a decline in ISA, spectrophotometric monitoring showed $\mathrm{Fe}$ (II) ingrowth, without production of VFAs, indicating that $\mathrm{Fe}$ (III) oxyhydroxide may have been used as TEA during the first stage of oxidation of ISA (Fig. $2 d$ and $e$ ). The $\mathrm{pH}$ remained stable over the whole incubation period, whilst the turbidity could not be analysed because of interference from the added $\mathrm{Fe}(\mathrm{III})$ oxyhydroxide. After c. 28 days, almost all of the ISA added had been metabolized, and $\sim 50 \%$ of the carbon (7.2 $\mathrm{mM}$ of the $15.7 \mathrm{mM} \mathrm{C}$ added) was accounted for as acetate, $n$-butyrate and propionate (Fig. $2 f$ ), possibly reflecting fermentative pathways. However, Fe(III) was continually reduced throughout the extended time course, even when ISA was depleted, and therefore Fe(III) reduction could have been coupled to either (1) the direct oxidation of ISA (especially early on in the incubation when a slow rate of $\mathrm{Fe}$ (III) reduction was linked to modest ISA degradation) or (2) to the oxidation of fermentation products that formed from this substrate and were detected after 21 days of incubation, when $\mathrm{Fe}(\mathrm{III})$ reduction was maximal. A minor fraction of the carbon removed was recovered in the gas phase as methane after ISA depletion, which increased steadily to $c .14 \%$ of the headspace volume after an prolonged incubation time of 200 days (Fig. 4). The missing c. $8.1 \mathrm{mM} \mathrm{C}$ (c. $52 \%$ ) may have been transformed into other carbon products and/or resulted in biomass production, which could not be detected in our analyses.

Under sulfate-reducing conditions, ISA degradation started after a lag phase of three to seven days and then continued quickly until all the ISA (2.72 mM ISA equivalent to $16.1 \mathrm{mM} \mathrm{C}$ ) was consumed after about 21 days (Fig. 3a). After 
a
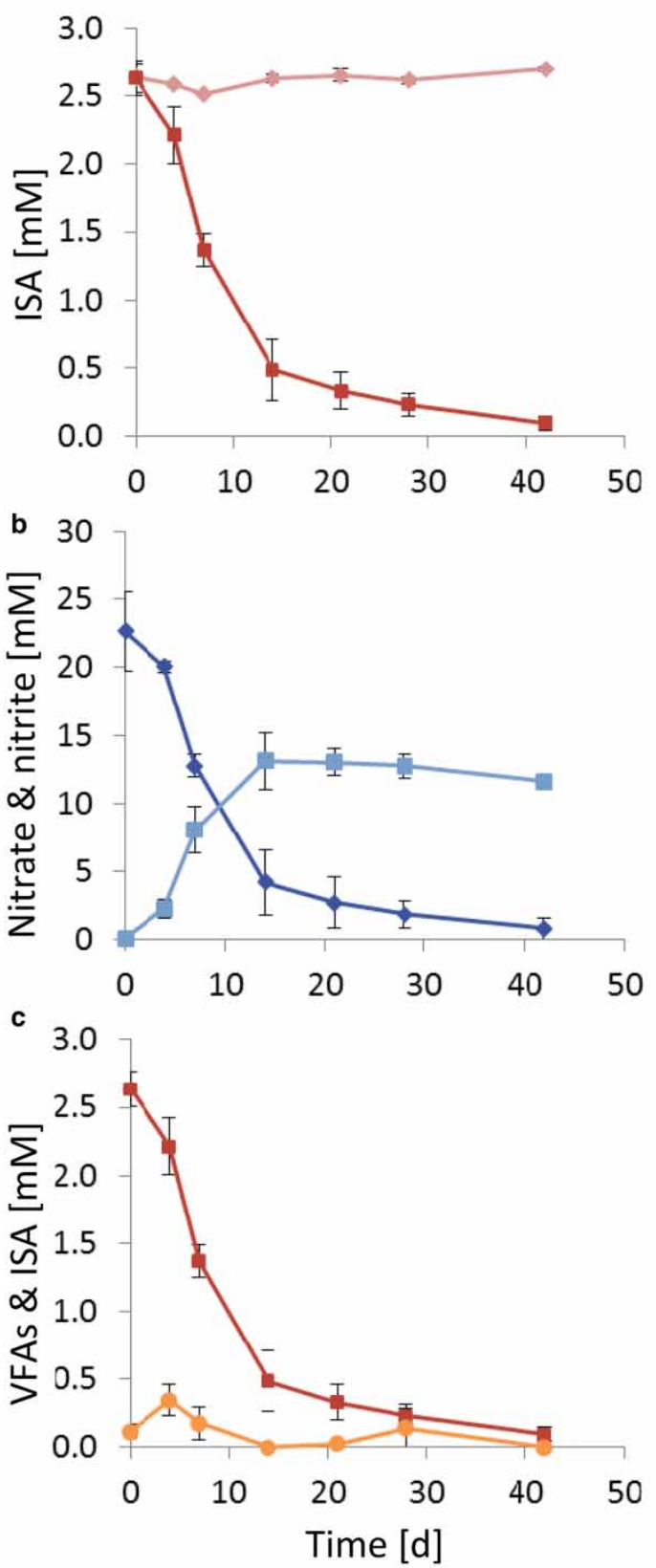

d

$\mathrm{Fe}(\mathrm{III})$ reduction
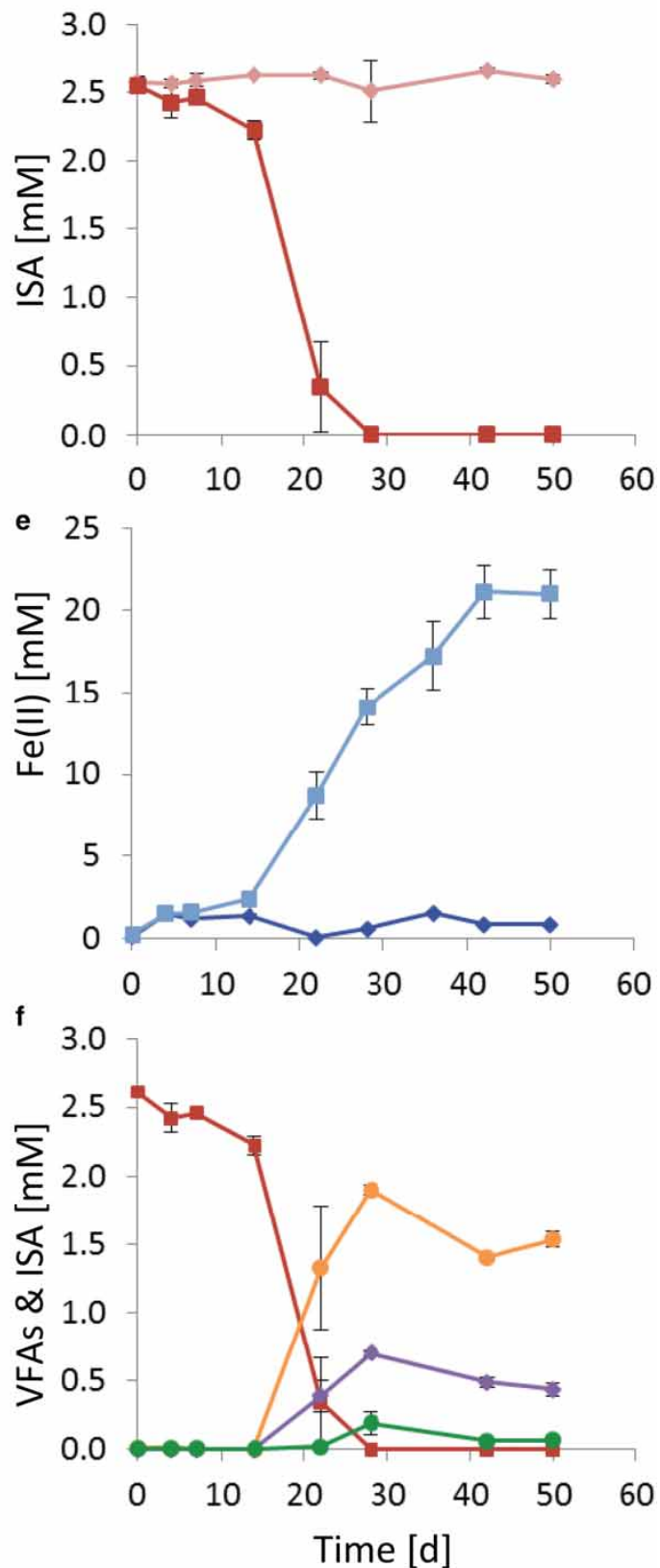

FIG. 2. Biodegradation of ISA by nitrate-reducing $(a-c)$ and Fe(III)-reducing cultures $(d-f)$ at a pH of 7. (a) ISA concentration: ( $\bullet$ ) test condition with active microbial inoculum; ( $\bullet$ sterile control (autoclaved). (b) Test sample: $(\bullet)$ nitrate; ( $₫)$ nitrite. (c) Ions in test condition: ( $\bullet$ ) ISA; ( $)$ acetate. (d) ISA concentration: ( () ) test condition with active microbial inoculum; (•) sterile control (autoclaved). (e) Fe(II) ingrowth: $(\bullet)$ sterile; $(\square)$ test condition. $(f)$ Ions in test condition: (๑) ISA; (๑) acetate; $(\bullet) n$-butyrate; $(\bullet)$ propionate. 


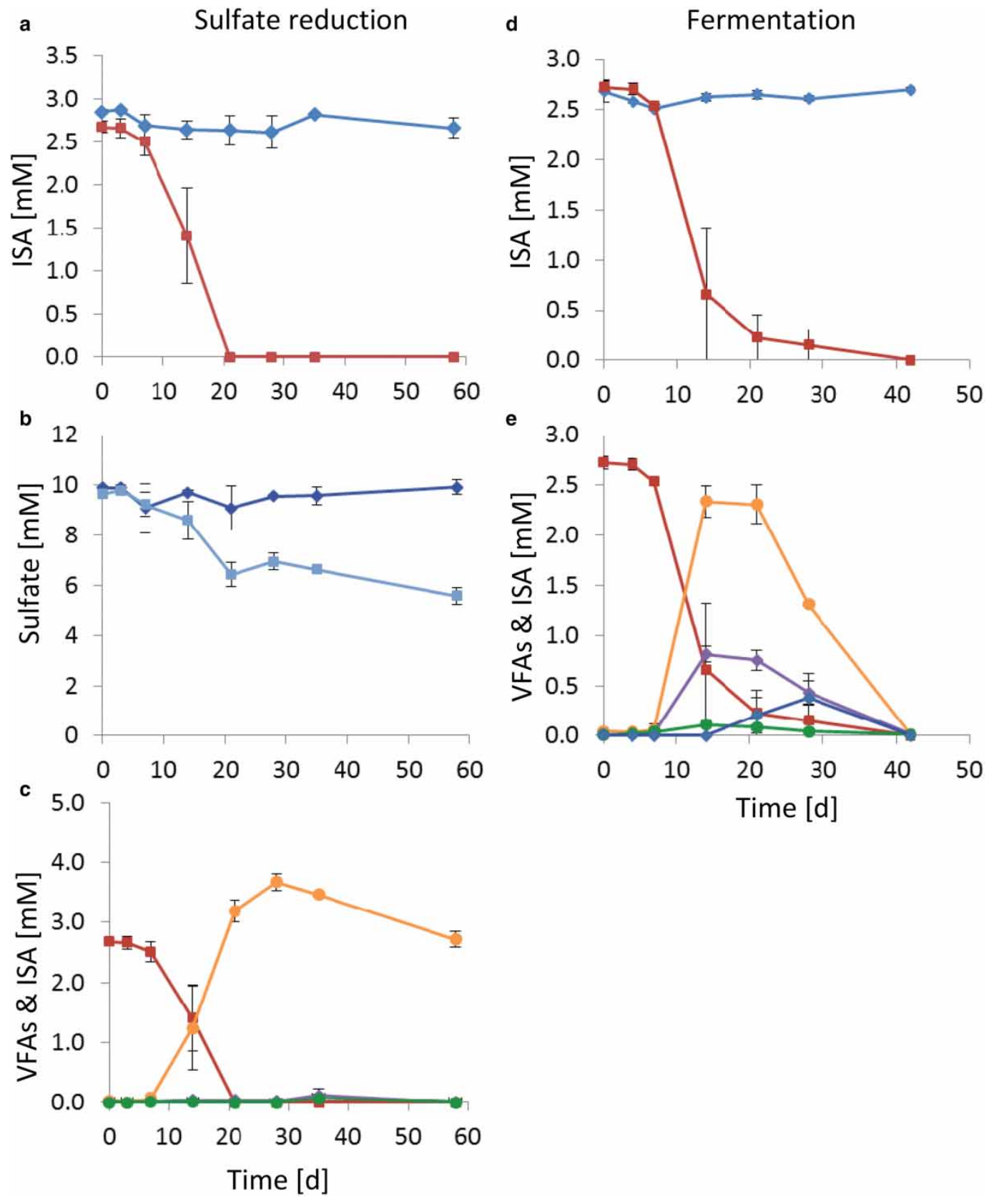

d Fermentation

FIG. 3. Biodegradation of ISA by sulfate-reducing cultures $(a-c)$ and in the absence of an added electron acceptor (fermentation) $(d-e)$ at a $\mathrm{pH}$ of 7. (a) ISA concentration: ( $\bullet$ ) test condition with active microbial inoculum; ( $\bullet$ ) sterile control (autoclaved). (b) Sulfate concentration: $(\bullet)$ sterile; ( $\bullet$ test. (c) Ions in test condition: (๑) ISA; (๑) acetate; $(\bullet) n$ butyrate; $(\bullet)$ propionate. $(d)$ ISA concentration: (®) test condition with active microbial inoculum; $(\bullet)$ sterile control

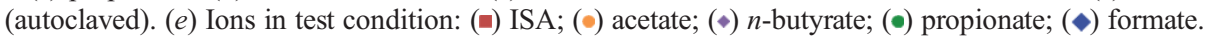




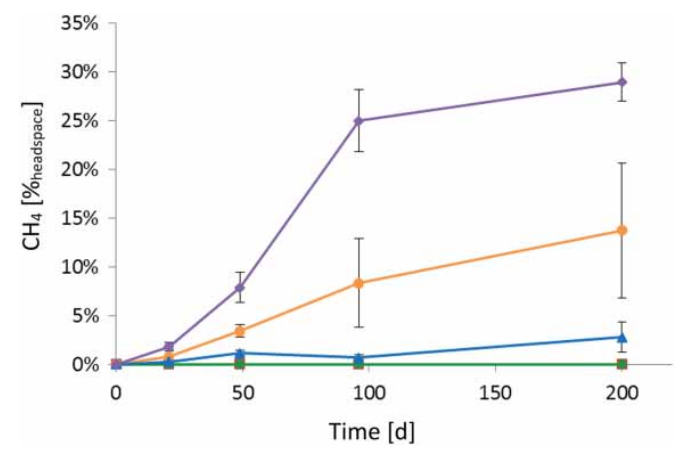

FIG. 4. Gas evolution during the biodegradation of ISA in sediment enrichment slurries containing $2 \mathrm{mM} \mathrm{Ca(ISA})_{2}$ under different biogeochemical conditions as follows: (Ш) sterile control sterile (autoclaved); (•) $24 \mathrm{mM} \mathrm{NaNO}_{3}$; (•) $20 \mathrm{mmol}^{-1} \mathrm{Fe}$ (III) oxyhydroxide; (৯) $12 \mathrm{mM} \mathrm{Na}_{2} \mathrm{SO}_{4}$;

(•) 'no added electron acceptor'.

c. 14 days there was a strong smell of sulfide, confirming microbial sulfate-reducing activity and the experiment turned from beige to a grey/black colour which was indicative of the formation of iron-sulfide phases. This was accompanied by the steady depletion of sulfate in the cultures (Fig. $3 b$ ). About $40 \%$ of the carbon from the ISA was converted to acetate, which was metabolized after the ISA had been depleted (Fig. 3c), presumably via sulfate reduction, with another $0.85 \mathrm{mM}$ sulfate reduced over this time. The $\mathrm{pH}$ of this sulfatereducing experiment remained stable at $c .7$, and the turbidity also fell from $\mathrm{OD}_{600 \mathrm{~nm}}=0.49$ to 0.40 . Given the geochemical profiles noted in this experiment, it is likely that both ISA and fermentation products from ISA were used as electron donors for sulfate reduction. Methane was detected ( $2.8 \%$ of the headspace after an extended incubation period of 200 days), but at lower levels than noted in the $\mathrm{Fe}(\mathrm{III})$-reducing cultures.

Finally, the fermentative pathways that were implied in the $\mathrm{Fe}(\mathrm{III})$ - and sulfate-reducing cultures, were explored in the no electron acceptor control experiment. Here, after an initial lag of about seven days, ISA was degraded efficiently and depleted after about 21 days, despite the absence of an added electron acceptor (apart from the $\mathrm{CO}_{2}$ added in the headspace of the bottles). Of the c. $16.3 \mathrm{mM} \mathrm{C}$ added as ISA, about $54 \%$ $(8.1 \mathrm{mM} \mathrm{C})$ was converted into VFAs, of which $4.7 \mathrm{mM} \mathrm{C}$ was converted to acetate and $3.2 \mathrm{mM}$ to $n$-butyrate, and smaller amounts to formate and propionate (Fig. 3e). Besides the fermentation of ISA to VFAs, larger quantities of methane were detected in comparison to all other experiments. Especially after the time point of ISA depletion, relatively high amounts of methane were formed, resulting in about $25 \% \mathrm{CH}_{4}$ of the headspace volume after 96 days which increased only slightly after another 100 days of incubation by $4 \%$ (Fig. 4), even though it still represented a small fraction of the total carbon metabolized. The main metabolic driving force in this incubation was clearly fermentation, while it is possible that methanogenesis could become more pronounced after long incubation times.

Attempts were made to monitor microbial growth by quantifying changes in turbidity, used successfully in previous studies on ISA biodegradation before (e.g. Strand et al., 1986; Bassil et al., 2014), but in all experiments increases in turbidity were minimal, and in many cases fell over time, in some experiments by up to $70 \%$. Interestingly, the turbidity of the sterile controls remained stable. Microscopic analyses, using the Hoechst 33342 dye to identify microbial cells, demonstrated that aggregates varying in size, and of up to $100 \mu \mathrm{m}$ in diameter, formed in the microbiologically active experiments. These were surrounded by viable planktonic rod-shaped cells of $\sim 2-4 \mu \mathrm{m}$ long (data not shown), which were clearly external to the aggregates and floating or actively moving in the medium.

The clumping noted in these experiments makes the accurate measurement of microbial growth by turbidity impossible. However, DNA profiling experiments were used to identify key changes in the microbial communities that dominated under the biogeochemical conditions imposed. Rarefaction curves (Fig. 5a) showed a dramatic decrease in microbial diversity, from the raw sediment sample ( $>500$ species), to the oxic samples incubated for 21 days (just over 100 species), while the anaerobic cultures contained only $\sim 50-100$ discrete gene sequences. Such a change in relative microbial abundance is common when selective conditions are imposed in microcosm experiments, for example with the addition of ISA as an electron donor, and an excess of electron acceptor, such as nitrate or $\mathrm{Fe}(\mathrm{III})$ under anoxic conditions (e.g. Thorpe et al., 2012; Williamson et al., 2013, Bassil et al., 2014). Figure $5 b$ shows the broad phylogenetic affiliations of the organisms detected. In the sediment inoculum no single species from these broad phylogenetic groups comprised more than $3 \%$ of the sequences detected. However, after 21 days incubation under aerobic conditions, when the ISA had been degraded fully, 

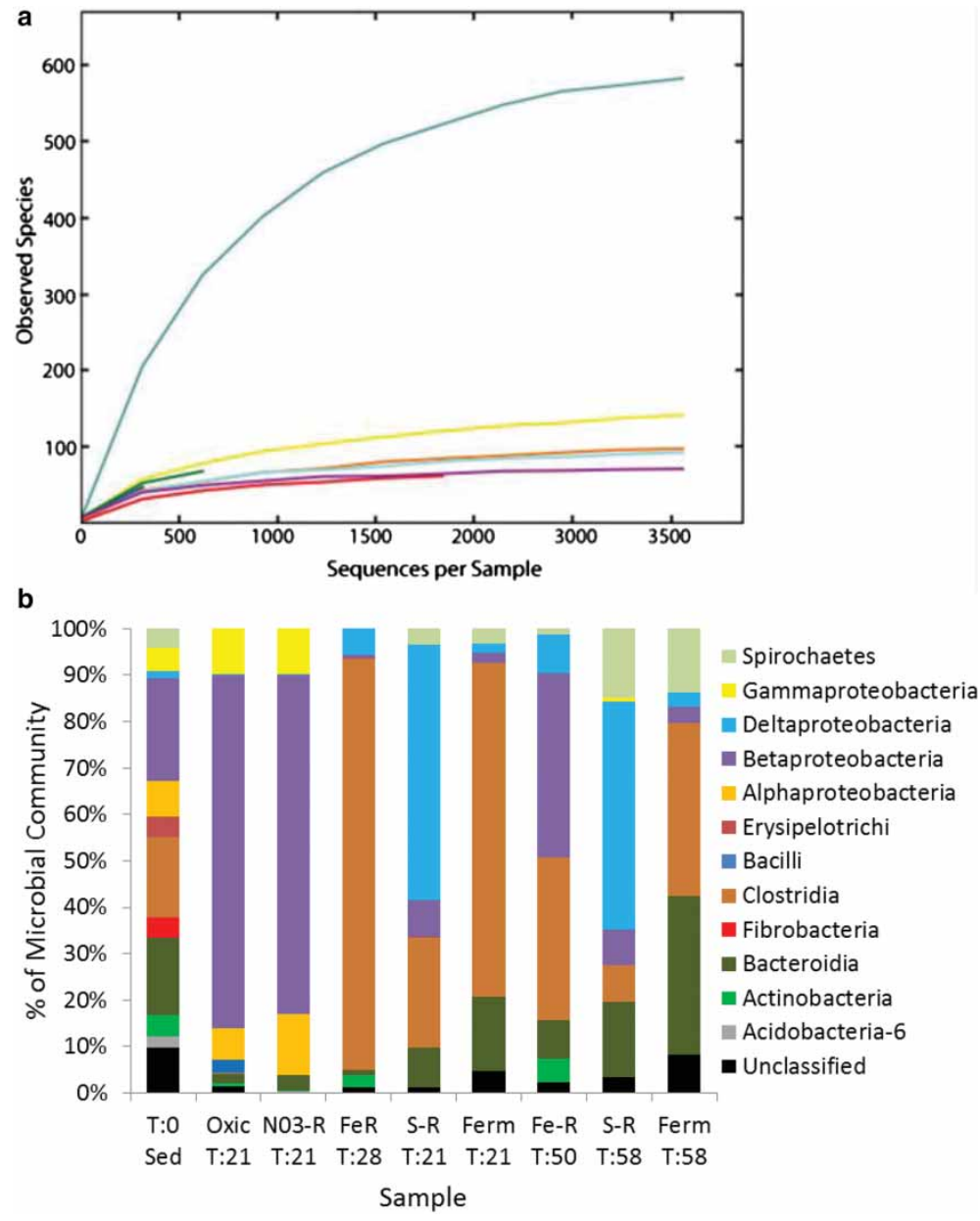

Fig. 5. Molecular ecology (16S rRNA gene) analysis of microbial ecology of sediment inoculum and microbial enrichments. (a) Alpha rarefaction plot showing number or observed species (distinct DNA sequences) in the sediment at day $0(\bullet)$, and after aerobic incubation at day $21(\bullet)$, nitrate reduction at day $21(\bullet), \mathrm{Fe}(\mathrm{III})$ reduction at day $28(\bullet)$ and 50 $(\varpi)$, sulfate reduction at day $21(\Xi)$ and day $58(\Xi)$, and with 'no added electron acceptor’ at day $21(\Xi)$ and day 58 ( $)$. (b) Microbial Community composition by phylogenetic classes in the corresponding samples.

the microbial community was dominated by a Betaproteobacterium most closely related $(97 \%$ sequence match) to Hydrogenophaga palleronii (Willems et al., 1989), a Gram-negative bacterium known to use hydrogen as an energy source, and also to oxidize organics (presumably ISA in this case) with oxygen as the TEA. In contrast, bacteria implicated in ISA degradation in the nitrate-reducing cultures included close relatives to known Betaproteobacteria ( $>98 \%$ sequence homology), including a member of the Comamonadaceae (34\% of sequences detected) and a close relative of Rhodoferax ferrireducens ( $15 \%$ of sequences).
The microbial community in the Fe(III)-reducing culture at 21 days was dominated by a novel organism most closely related $(96 \%$ sequence match) to an uncultured organism in the Grampositive class Clostridia ( $83 \%$ of genes detected). Interestingly, organisms most closely related to known Fe(III)-reducers were in low relative abundance (e.g. $<1 \%$ of species affiliated with $\mathrm{Fe}(\mathrm{III})-$ reducing Geobacter species (Lovley et al., 1987; Lloyd, 2003) at 21 days. By day 50, this culture was dominated ( $40 \%$ of sequences) by a close relative (99\% sequence similarity) to Dechlorosoma suillum, a perchlorate-reducing Betaproteobacterium. The 


\section{G. KUIPPERS ETAL.}

selection for organisms not normally associated with the reduction of insoluble Fe(III) oxyhydroxide, may be due to the inclusion of the strong chelating agent ISA, in these experiments which could change dramatically the bioavailability of Fe(III), and hence the mechanism of reduction. It is also possible that $\mathrm{Fe}(\mathrm{III})$ reduction could have been linked directly to co-factor regeneration associated with fermentation of ISA.

It should be noted that the majority of the microbial community in the fermentation experiments ('no added electron acceptor'), were also affiliated with Gram-positive Clostridia. In sharp contrast, the sulfate-reducing cultures were dominated by organisms well known to respire sulfate at neutral $\mathrm{pH}$; approximately $50 \%$ of the community was affiliated with the Deltaproteobacterium Desulfovibrio idahonensis after 21 and 50 days, and the role of this organism in ISA biodegradation clearly warrants investigation.

\section{Conclusion}

In this study, we have confirmed that the microbial degradation of ISA occurs under a range of biogeochemical conditions at circumneutral $\mathrm{pH}$, representative of the geosphere surrounding a potential GDF. In keeping with a previous study conducted at pH 10 (Bassil et al., 2014) microorganisms were shown to degrade ISA under aerobic, nitrate-, and $\mathrm{Fe}(\mathrm{III})$-reducing conditions. However, in this study, ISA was also degraded under sulfate-reducing conditions, in sharp contrast to the high-pH system, where the diminishing energy yield under alkaline conditions prevented measurable sulfate reduction over the time-scale of the experiments. The precise mechanisms of ISA degradation in these $\mathrm{pH} 7$ experimental systems clearly warrant further attention, including fermentative pathways implicated in the Fe(III)- and sulfate-reducing experiments, in addition to direct coupling of ISA oxidation to anaerobic metabolism, e.g. during nitrate reduction. Subsequent conversion of the initial ISA degradation products to methane was also confirmed in these experiments, and the addition of electron acceptors that could compete with microbially derived $\mathrm{CO}_{2}$ during methanogenesis (i.e. nitrate, $\mathrm{Fe}(\mathrm{III})$ and sulfate) had a dramatic impact on the yield of methane. The impact of a range of biogeochemical processes on the end products of ISA biodegradation is clearly an area where further research would be valuable, as is the controlling role of microbial metabolism on the mobility of priority radionuclides during ISA metabolism, especially in sulfidic systems. Sulfate-reduction may eventually dominate in and around a GDF, as sulfate in cements and groundwaters can be present at around $9 \mathrm{mM}$ in brackish saline waters, and up to $50 \mathrm{mM}$ in other UK groundwaters (Metcalfe et al., 2007), resulting in the formation of poorly soluble sulfide phases that could immobilize a broad range of radionuclides.

\section{Acknowledgements}

This work was supported by the Radioactive Waste Management (RWM). We would like to thank Alastair Bewsher and Paul Lythgoe (The University of Manchester) for analytical support.

\section{References}

Askarieh, M.M., Chambers, A.V., Daniel, F.B.D., FitzGerald, P.L., Holtom, G.J., Pilkington, N.J. and Rees, J.H. (2000) The chemical and microbial degradation of cellulose in the near field of a repository for radioactive wastes. Waste Management, 20, 93-106.

Bailey, M.J. (1986) Utilization of glucoisosaccharinic acid by a bacterial isolate unable to metabolize glucose. Applied Microbiology and Biotechnology, 24, 493-98.

Bassil, N.M., Bryan, N. and Lloyd, J.R. (2014) Microbial degradation of isosaccharinic acid at high $\mathrm{pH}$. The ISME Journal, 1-11.

Bond, K.A. and Tweed, C.J. (1995) Groundwater compositions for the Borrowdale Volcanic Group, boreholes 2, 4 and RCF3, Sellafield, evaluated using thermodynamic modelling. Nirex, NSSIR397.

Booth, W. (1987) Postmortem on Three Mile Island. Science, 238, 1342-1345.

Bradbury, M.H. and Sarott, F.A. (1995) Sorption databases for the cementitious near-field of a L/ILW repository for performance assessment. PSI-Bericht 95-06; Paul Scherrer Institute: Villigen, Switzerland.

Brown, A.R., Wincott, P.L., LaVerne, J.A., Small, J.S., Vaughan, D.J., Pimblott, S.M. and Lloyd, J.R. (2014) The impact of ionizing radiation on the bioavailability of $\mathrm{Fe}$ (III) minerals for microbial respiration. Environmental Science \& Technology, 48, 10672-10680.

Caporaso, J.G., Stombaugh, J., Costello, E.K., Lozupone, C.A. et al. (2010) QIIME allows analysis of highthroughput community sequencing data. Nature Methods, 7, 335-336.

Cole, J.R., Wang, Q., Cardenas, E., Fish, J., Chai, B., Farris, R.J., Kulam-Syed-Mohideen, A.S., McGarrell, D.M., Marsh, T., Garrity, G.M. and Tiedje, J.M. (2009) 
The Ribosomal Database Project: improved alignments and new tools for rRNA analysis. Nucleic Acids Research, 37, D141-D145.

DECC (2014) Implementing Geological Disposal; A framework for the long-term management of higher activity radioactive waste. URN 14D/235. Department of Energy \& Climate Change, London.

Edgar, R.C. (2010) Search and clustering orders of magnitude faster than BLAST. Bioinformatics, 26, 2460-2461.

Gaona, X., Montoya, V. , Colas, E., Grive, M. and Duro, L. (2008) Review of the complexation of tetravalent actinides by ISA and gluconate under alkaline to hyperalkaline conditions. Journal of Contaminant Hydrology, 102, 217-227.

Glaus, M.A. and van Loon, L.R. (2008) Degradation of cellulose under alkaline conditions: New insights from a 12 years degradation study. Environmental Science \& Technology, 42, 2906-2911.

Glaus, M.A., van Loon, L.R., Achatz, S., Chodura, A. and Fischer, K. (1999) Degradation of cellulosic materials under the alkaline conditions of a cementitious repository for low and intermediate level radioactive waste part I: Identification of degradation products. Analytica Chimica Acta, 398, 111-122.

Knill, C.J. and Kennedy, J.F. (2003) Degradation of cellulose under alkaline conditions. Carbohydrate Polymers, 51, 281-300.

Lane, D. (1991) 16S/23S rRNA sequencing. Pp. 115-175 in: Nucleic Acid Techniques in Bacterial Systematics (E. Stackelbrandt and M. Goodfellow, editors). John Wiley \& Sons, Chichester, UK.

Lloyd, J.R. (2003) Microbial reduction of metals and radionuclides. FEMS Microbiology Reviews, 27, 411-425.

Lloyd, J.R. and Macaskie, L.E. (2000) Bioremediation of radioactive metals. Pp. 277-327 in: Environmental Microbe-Metal Interactions (D.R. Lovley, editor). ASM Press.

Lovley, D.R. and Phillips, E.J.P. (1987) Rapid assay for microbially reducible ferric iron in aquatic sediments. Applied Environmental Microbiology, 53, 1536-1540.

Lovley, D.R., Greening, R.C. and Ferry, J.G. (1984) Rapidly growing rumen mathanogenic organism that synthesizes coenzyme-M and has a high-affinity for formate. Appied. Environmental Microbiology, 48, 81-87.

Lovley, D.R., Stolz, J.F., Nord, G.L. and Phillips, E.J.P. (1987) Anaerobic production of magnetite by a dissimilatory iron-reducing microorganism. Nature, 330, 252-254.

Metcalfe, R., Crawford, M.B., Bath, A.H., Littleboy, A. K., Degnan, P.J. and Richards, H.G. (2007) Characteristics of deep groundwater flow in a asin marginal setting at Sellafield, Nothwest England: $36 \mathrm{Cl}$ and halide evidence. Applied Geochemistry, 22, 128-151.
Mozdyniewicz, D.J., Nieminen, K. and Sixta, H. (2013) Alkaline steeping of dissolving pulp. Part I: cellulose degradation kinetics. Cellulose, 20, 1437-1451.

Muyzer, G., Teske, A., Wirsen, C.O., Jannasch, H.W. (1995) Phylogenetic relationships of Thiomicrospira species and their identification in deep-sea hydrothermal vent samples by denaturing gradient gel electrophoresis of $16 \mathrm{~S}$ rDNA fragments. Archives of Microbiology, 164, 165-172.

NDA (2010) Geological Disposal; Near-field Evolution Status Report. NDA/RWMD, 033, Didcot, UK, 59-62.

Pavasars, I., Hagberg, J., Borén, H. and Allard, B. (2003) Alkaline degradation of cellulose: Mechanisms and kinetics. Journal of Polymers and the Environment, 11, 39-47.

Rai, D., Hess, N.J., Xia, Y., Rao, L., Cho, H.M., Moore, R.C. and van Loon, L.R. (2003) Comprehensive thermodynamic model applicable to highly acidic to basic conditions for isosaccharinate reactions with $\mathrm{Ca}(\mathrm{II})$ and $\mathrm{Np}(\mathrm{IV})$. Journal of Solution Chemistry, 32, 665-689.

Rizoulis, A., Steele, H.M., Morris, K. and Lloyd, J.R. (2012) The potential impact of anaerobic microbial metabolism during the disposal of intermediate-level waste. Mineralogical Magazine, 76, 3261-3270.

Shen, Q.R., Ran, W. and Cao, Z.H. (2003) Mechanisms of nitrite accumulation occurring in soil nitrification. Chemosphere, 50, 747-753.

Strand, S.E., Dykes, J. and Chiang, V. (1986) Aerobic microbial degradation of glucoisosaccharinic acid. Applied Environmental Microbiology, 47, 268-271.

Thorpe, C.L., Law, G.T.W., Boothman, C., Lloyd, J.R., Burke, I.T. and Morris, K. (2012). The synergistic effects of high nitrate concentrations on sediment bioreduction. Geomicrobiology Journal, 29, 484-493.

Tits, J., Wieland, E. and Bradbury, M.H. (2005) The effect of isosaccharinic acid and gluconic acid on the retention of $\mathrm{Eu}(\mathrm{III}), \mathrm{Am}(\mathrm{III})$ and Th(IV) by calcite. Applied Geochemistry, 20, 2082-2096.

Van Loon, L.R. and Glaus, M.A. (1998) Experimental and theoretical studies on alkaline degradation of celluloseandits impact on the sorption of radionuclides; PSI Bericht, 98-07; Paul Scherrer Institut: Villigen, Switzerland. Also published as: Van Loon, L.R. and Glaus, M.A. (1998) NTB, 97-04; Nagra: Wettingen, Switzerland.

Van Loon, L.R., Glaus, M., Stallone, S. and Laube, A. (1997) Sorption of isosaccharinic acid, a cellulose degradation product, on cement. Research Communications, Environmental Sciences \& Technology, 31, 1243-1245.

Van Loon, L.R., Glaus, M.A., Laube, A. and Stallone, S. (1999) Degradation of cellulosic materials under the 


\section{G. KUIPPERS ETAL.}

alkaline conditions of a cementitious repository for low- and intermediate-level radioactive waste. Part II: Degradation kinetics. Journal for Environmental Polymer Degradation, 7, 41-51.

Vercammen, K., Glaus, M.A. and van Loon, L.R. (1999) Complexation of calcium by alpha-isosaccharinic acid under alkaline conditions. Acta Chemica Scandinavica, 53, 241-246.

Vercammen, K., Glaus, M.A. and van Loon, L.R. (2001) Complexation of Th(IV) and $\mathrm{Eu}(\mathrm{III})$ by $\alpha$-isosaccharinic acid under alkaline conditions. Radiochimica Acta, 89, 393-401.

Warwick, P., Evans, N., Hall, T. and Vines, S. (2003) Complexation of $\mathrm{Ni}(\mathrm{II})$ by $\alpha$-isosaccharinic acid and gluconic acid from $\mathrm{pH} 7$ to $\mathrm{pH}$ 13. Radiochimica Acta, 91, 233-240.

Warwick, P., Evans, N., Hall, T. and Vines, S. (2004) Stability constants of uranium(IV)- $\alpha$-isosaccharinic acid and gluconic acid complexes. Radiochimica Acta, 92, 897-902.
Whistler, R.L. and BeMiller, J.N. (1958) Alkaline degradation of polysaccharides. Advances in Carbohydrate Chemistry, 13, 289-329.

Willems, A., Busse, J., Goor, M., Pot, B., Falsen, E., Jantzen, E., Hoste, B., Gillis, M., Kersters, K., Auling, G. and De Ley, J. (1989). Hydrogeneophaga a new genus of hydrogen-oxidizing bacteria that includes Hydrogenophaga flava comb. nov. (formerly Pseudomonas flava), Hydrogenophaga palleronii (formerly Pseudomonas palleronii, Hydrogenophaga pseudoflava (formerly Pseudomonas pseudoflava and "Pseudomonas carboxydoflava"), and Hydrogenophaga taeniospialis (formerly Pseudomonas taeniospiralis). International Journal of Systematic Bacteriology, 39, 319-333.

Williamson, A.J., Morris, K., Shaw, S., Byrne, J.M., Boothman, C. and Lloyd, J.R. (2013) Microbial reduction of $\mathrm{Fe}$ (III) under alkaline conditions relevant to geological disposal. Applied and Environmental Microbiology, 79, 3320-3326. 